\title{
Bacillus Subtilis in PVA Microparticles for Treating Open Wounds
}

Noa Ben David, ${ }^{a}{ }^{\S}$ Mahsa Mafi, ${ }^{b}$ Abraham Nyska, ${ }^{c}$ Adi Gross, ${ }^{a}$ Andreas Greiner, ${ }^{b *}$ and Boaz Mizrahia $^{*}$

aTechnion- Israel Institute of Technology, Faculty of Biotechnology and Food Engineering, Haifa 3200003, Israel.

${ }^{b}$ Faculty of Biology, Chemistry and Earth Sciences, Bayreuth Center for Colloids and Interfaces, University of Bayreuth, 95440, Germany.

cTel Aviv University and Consultant in Toxicologic Pathology, Tel Aviv, Israel.

\section{Table of contents}

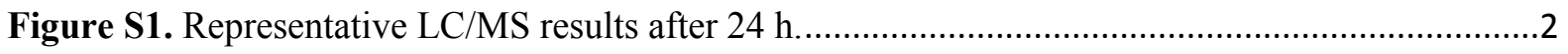

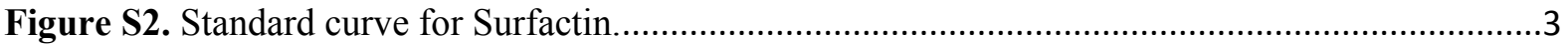

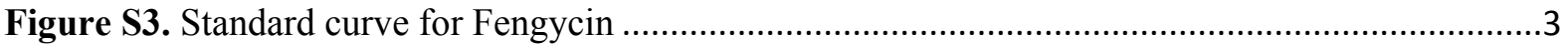

Figure S4. Inhibition zone of $B$. subtilis particles on $S$. aureus and MRSA. ...........................................4 
Supporting information for $\boldsymbol{B}$. subtilis analysis.

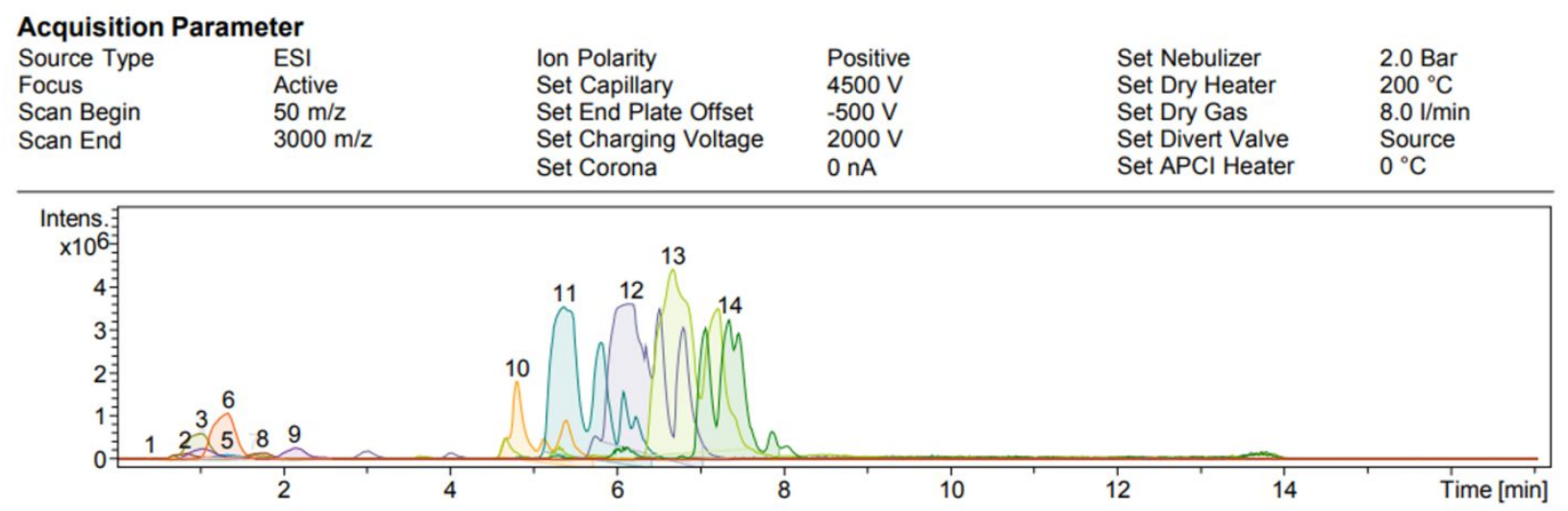

\begin{tabular}{|c|c|c|c|c|c|}
\hline & \# & RT (min) & Area & $\begin{array}{c}\text { Molecular } \\
\text { weight (Da) }\end{array}$ & Homologue $\mathrm{e}^{1-2}$ \\
\hline \multirow{9}{*}{ Fengycin } & 1 & 0.4 & 271032 & 1447.6 & C-15 \\
\hline & 2 & 0.8 & 2192678 & 1463.6 & C-16 \\
\hline & 3 & 1.0 & 10772007 & 1477.6 & C-17 \\
\hline & 4 & 1.0 & 5175846 & 1491.6 & C-16 \\
\hline & 5 & 1.3 & 1714215 & 1447.6 & C-15 \\
\hline & 6 & 1.3 & 20101642 & 1505.6 & $\mathrm{C}-17$ \\
\hline & 7 & 1.7 & 863686 & 1477.6 & $\mathrm{C}-17$ \\
\hline & 8 & 1.8 & 2908412 & 1463.6 & C-16 \\
\hline & 9 & 2.1 & 4720794 & 1491.6 & C-16 \\
\hline \multirow{5}{*}{ Surfactin } & 10 & 4.8 & 38730508 & 994.6 & $\mathrm{C}-12$ \\
\hline & 11 & 5.4 & 129026040 & 1008.6 & $\mathrm{C}-13$ \\
\hline & 12 & 6.2 & 158873792 & 1022.6 & C-14 \\
\hline & 13 & 6.7 & 168789808 & 1036.6 & $\mathrm{C}-15$ \\
\hline & 14 & 7.3 & 91685792 & 1050.6 & C-16 \\
\hline
\end{tabular}

Figure S1. Representative LC/MS results after $24 \mathrm{~h}$. 

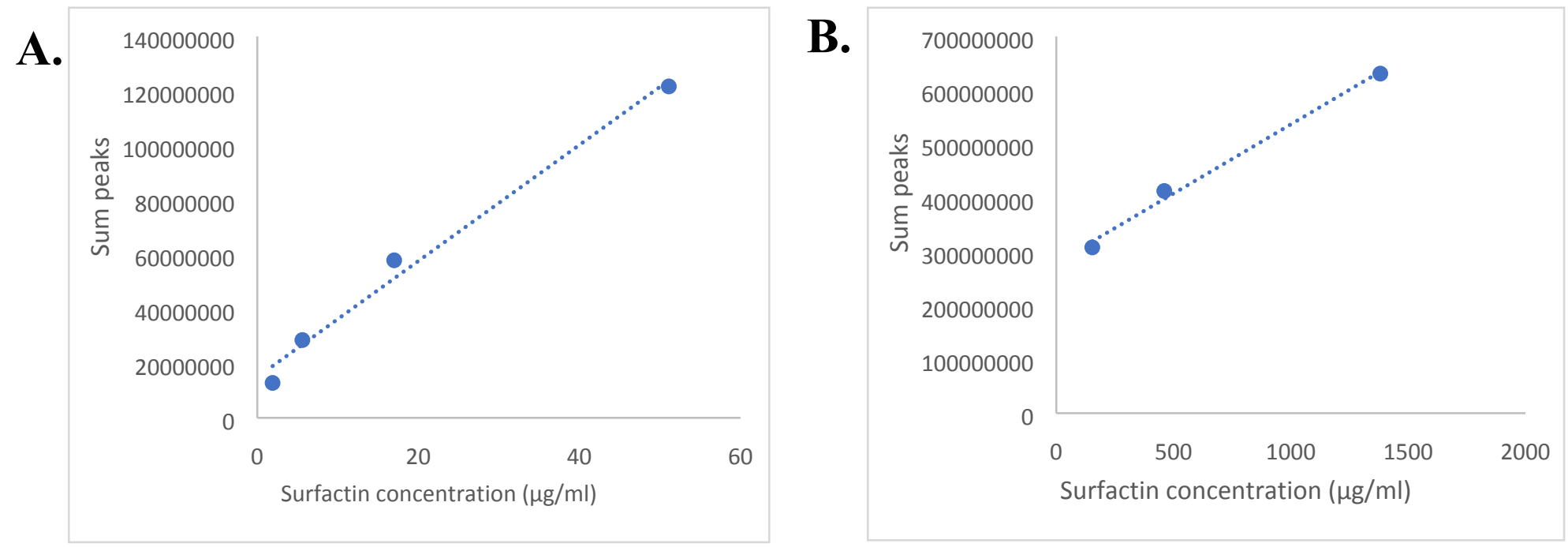

Figure S2. Standard curve for Surfactin. A. low values B. high values.

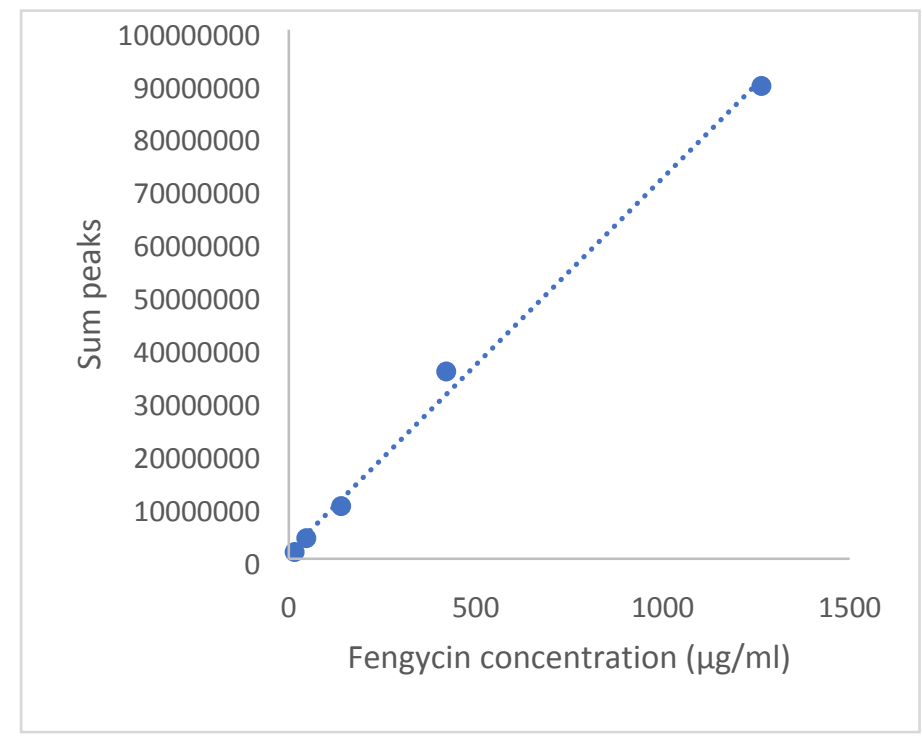

Figure S3. Standard curve for Fengycin 

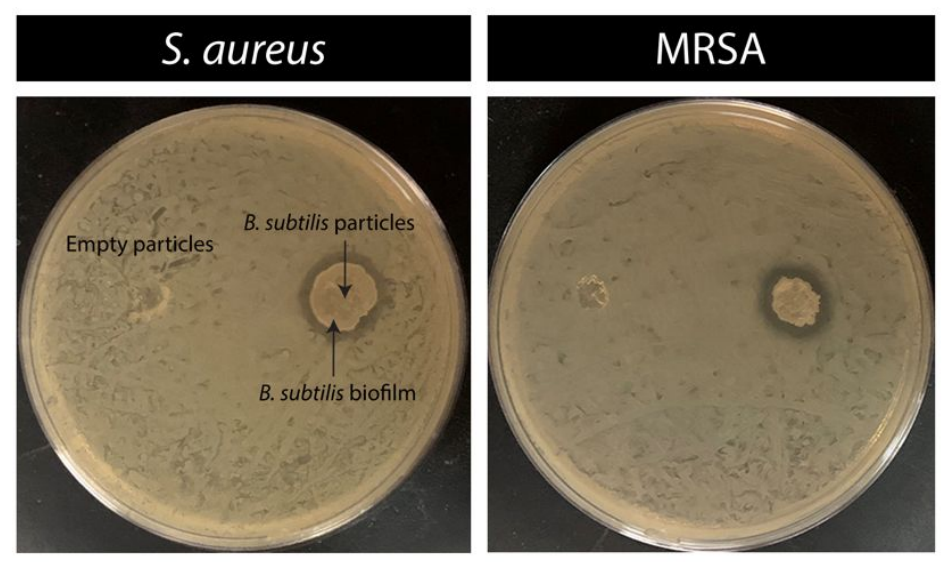

Figure S4. Inhibition zone of B. subtilis particles on s. aureus and MRSA. In both plates, empty particles were placed on the left side and B. subtilis particles on the right side.

\section{References}

1. Malfanova, N.; Franzil, L.; Lugtenberg, B.; Chebotar, V.; Ongena, M., Cyclic lipopeptide profile of the plant-beneficial endophytic bacterium Bacillus subtilis HC8. Arch. Microbiol. 2012, 194 (11), 893-899.

2. $\quad$ Sa, R.-B.; An, X.; Sui, J.-K.; Wang, X.-H.; Ji, C.; Wang, C.-Q.; Li, Q.; Hu, Y.-R.; Liu, $\mathrm{X}$., Purification and structural characterization of fengycin homologues produced by Bacillus subtilis from poplar wood bark. Australas. Plant Pathol. 2018, 47 (3), 259-268. 